\title{
rec
}

Revista Eletrônica de Ciência Política v. 10 , n. 1 (2019), 59-76 DOI: $10.5380 /$ recp.v\%vi\%i.70423 https://revistas.ufpr.br/politica/

\section{Dinheiro, eleições e representação política: uma análise dos padrões de financiamento das campanhas nas eleições de 2014 e 2016 em uma perspectiva dos gêneros}

\author{
Valdenize Gurjão Corrêa \\ Mestre, Universidade Federal do Pará - UFPA \\ Rodrigo Dolandeli dos Santos \\ Doutor, Universidade Federal do Pará - UFPA
}

\begin{abstract}
O debate sobre eleições e representação política no Brasil tem destacado as dificuldades das mulheres em chegarem aos cargos eletivos, devido, entre outros fatores, aos embaraços impostos pelo sistema de financiamento que tem se mostrado extremamente desigual na comparação entre homens e mulheres. Diante essa questão, a presente pesquisa tem como objetivo principal: avaliar o padrão de financiamento das campanhas eleitorais das mulheres em relação aos homens para a Câmara dos Deputados, Assembleias Legislativas e Câmara de Vereadores, nas eleições de 2014 e 2016. Utilizou-se os softwares SPSS para processamento dos métodos estatísticos descritivos e inferenciais por meio de estimativas de média, desvio padrão, variância e teste de análise de variância (ANOVA). Deste modo, constatou-se que as mulheres arrecadam um volume de recursos inferior aos homens, independentemente do cargo em disputa, ideologia partidária ou região do país. Diante às análises e perspectivas abordadas ao longo da pesquisa, observou-se que os diferentes padrões utilizados no financiamento de campanha das mulheres, dificultam a construção social e inclusiva de uma política representativa. Evidenciando que a democracia brasileira se encontra longe de alcançar um patamar de igualdade política entre os gêneros.
\end{abstract}

Palavras-chave: Eleições; financiamento de campanha; representação política.

\section{INTRODUÇÃO'}

Nas últimas décadas, a representação feminina no âmbito político, vem sendo questionada e ganhando espaço no campo acadêmico, movimentos feministas, instâncias partidárias e em importantes agendas nacionais e internacionais.

Diante desse tema, se discute os fatores que têm contribuído para o quadro de de-

\footnotetext{
${ }^{1}$ Este artigo apresenta as principais conclusões da pesquisa realizada por Valdenize Gurjão Corrêa, sob orientação do professor Dr Carlos Augusto da Silva Souza, no decorrer do curso de Mestrado do Programa de Pós-Graduação em Ciência Política da Universidade Federal do Pará.
} 
sigualdade entre os gêneros nos cargos eletivos. Dentre eles, destaca-se o financiamento de campanha, dada a alta correlação entre as receitas e as chances de sucesso eleitoral, juntamente com a baixa disposição das mulheres na arrecadação de recursos (SACCHET; SPECK, 2012).

No âmago dessas questões, percebe-se que ao longo dos tempos, a mulher vem percorrendo uma longa batalha pelo direito de votar e ser votada, de modo a conquistar marcos importantes pela ampliação de seus espaços, sobretudo no âmbito político. "Nos últimos anos, o número de mulheres presentes em cargos de tomada de decisão política tornou-se um dos indicadores da qualidade da democracia e um dos focos centrais de ação dos movimentos de mulheres em diferentes países do mundo" (SACCHET, 2009).

Entretanto, ao avaliar o contexto político brasileiro, observa-se que os resultados das eleições nos últimos 10 anos apontam para a mesma conclusão: houve avanços, mas poucos significativos. E que ainda não representam as expectativas desejadas.

Dentre os entraves à representação política feminina, pesquisadores ressaltam a importância dos recursos financeiros para o sucesso eleitoral (Samuels, 2005; Sacchet e Speck, 2012; Santos, 2011; Santos e Tanaka, 2016; Rodrigues, 2016) e reafirmam que, no decorrer dos últimos anos, várias mudanças vêm acontecendo em torno da participação das mulheres no parlamento. No entanto, essas mudanças não apresentam um aumento significativo, seja na esfera municipal, estadual ou federal.

Diante desse cenário, buscou-se reunir dados/informações com o propósito de responder a seguinte questão problema de pesquisa: Quais as diferenças nos padrões de financiamento das campanhas eleitorais das mulheres em relação aos homens nas eleições federais, estaduais e municipais nas regiões brasileiras?

Nesse sentido, realizou-se a análise dos dados pesquisados em consonância com os objetivos propostos nessa investigação, sendo o objetivo principal: avaliar o padrão de financiamento das campanhas eleitorais das mulheres em relação aos homens para a Câmara dos Deputados, Assembleias Legislativas e Câmara de Vereadores, nas eleições de 2014 e 2016. E objetivos específicos: descrever as diferenças na arrecadação de recursos nas campanhas de mulheres e homens eleitos em relação ao cargo em disputa; identificar as diferenças na distribuição dos recursos financeiros das candidaturas de mulheres e homens eleitos em relação à ideologia partidária; perceber as alterações nas fontes de financiamento das mulheres e homens eleitos em relação às regiões sob o qual representam.

A relevância dessa pesquisa está na contribuição que ela poderá trazer para os estudos mais atuais, considerando que o financiamento de campanha é um tema atual e polêmico, justamente por estar intrinsecamente relacionado ao aspecto que pode ser decisivo no resultado de uma eleição, o dinheiro.

Nesse sentido, este trabalho busca contribuir para o aprofundamento de outros estudos sobre o tema financiamento de campanha, estimular a reflexão e debates sobre a importância de se entender as problemáticas políticas em nosso país, dentre elas, as complexidades econômicas que compõe a arrecadação de recursos entre mulheres e homens, e ainda perceber as implicações desse processo na desigualdade de representações no contexto brasileiro. 


\section{METODOLOGIA}

Optou-se por realizar um estudo descritivo fundamentado nos pressupostos de uma abordagem quantitativa, que se baseia nos trabalhos com dados numéricos e técnicas estatísticas tanto para classificar como para analisar os resultados (FERNANDES, 2009).

Dessa forma, a pesquisa utilizou o banco de dados relativo à prestação de contas disponíveis no site do Tribunal Superior Eleitoral de todos os candidatos eleitos que disputaram a eleição de 2014 e 2016 nas diversas regiões, estados e municípios que compõem a federação brasileira.

Os instrumentos de coleta dos dados foram preferencialmente estabelecidos através da elaboração de planilhas, por meio do processamento no sistema Microsoft Excel e Statistic Package for Social Sciences (SPSS) versão 24.0, todos em ambiente Windows 7, que possibilitam agregar e processar os dados a partir dos seguintes marcadores: por candidato eleito, origem do recurso, valor do recurso, partido do candidato, sexo do candidato, estado, município, região, entre outras.

A população alvo da pesquisa foi constituída por todas as candidatas e candidatos eleitos para a Câmara dos Deputados, Assembleias Legislativas e Câmara de Vereadores, no ano de 2014 e 2016.

Utilizou-se ainda medidas de frequência absoluta e relativa para analisar a distribuição da variável dependente em função das variáveis independentes e medidas de posição e dispersão, como média, desvio padrão e mediana para descrever as receitas das campanhas.

Na parte inferencial da análise, foram utilizados os testes estatísticos Análise de Variância (ANOVA) para analisar a significância das diferenças ocorridas na variável dependente em função das variáveis independentes.

Para informações mais detalhadas sobre as diferenças entre médias apontadas no teste da ANOVA, foi utilizado um método de múltiplas comparações como o método de Tukey. Por último, para a análise geográfica dos padrões de financiamento das campanhas eleitorais, foi realizado o mapeamento da variável dependente nas cinco regiões brasileiras, por meio da Geoestatística, com a finalidade de identificar a presença de padrões.

Para esta pesquisa, o foco de análise é a média com base nos valores totais de arrecadação, pois se pretende em um próximo trabalho ponderar esses dados por UF.

\section{A IMPORTÂNCIA DO FINANCIAMENTO NAS COMPETIÇÕES ELEITORAIS}

Os recursos financeiros têm função preponderante no processo eleitoral. Sem eles, o candidato não pode adequadamente desempenhar tarefas centrais, tais como montar um comitê, se comunicar com o eleitor, apresentar suas propostas, fazer publicidade e divulgar suas ideias (SACCHET; SPECK, 2012). 
Deste modo, não é exagero afirmar que as campanhas eleitorais dependem fortemente de recursos financeiros. Para Sacchet e Speck (2011), o financiamento é tão importante que, sem eles, torna-se difícil para os candidatos realizarem outras atividades de campanha como, por exemplo, deslocar-se até diferentes localidades para discutir programas e apresentar sua candidatura, reunir equipes de trabalho visando a organização da campanha e a elaboração de propostas de governo, produzir material publicitário e fazer pesquisas junto ao eleitorado para avaliar os rumos da campanha.

Nesse contexto, fica claro que o objetivo do financiamento é arcar com as despesas para a promoção das campanhas eleitorais, de modo a assegurar a igualdade entre os candidatos e partidos (GOMES, 2012).

Assim, assegurar a distribuição igualitária de financiamento entre homens e muIheres contribui para a construção de uma democracia mais inclusiva, fortalecida e condizente aos direitos sociais assegurados na legislação brasileira. Pois, de acordo com o art. $1^{\circ}$, inciso $\mathrm{V}$ da constituição Federal/88:

\footnotetext{
A República Federativa do Brasil, formada pela união indissolúvel dos Estados e Municípios e do Distrito Federal, constitui-se em Estado Democrático de Direito e tem como fundamentos:

$(\ldots)$

V - o pluralismo político. (BRASIL, 1988).
}

Observa-se que, desde a redemocratização do país em 1988, há uma indissociabilidade entre o poder econômico e o poder político, principalmente no que tange ao financiamento de campanhas eleitorais. Dessa forma, faz-se necessário uma análise do financiamento das campanhas eleitorais, com enfoque nas doações destinadas às muIheres. Considerando que as mulheres têm doações diferentes em relação aos homens, podendo se constituir um fator que explica a baixa representatividade e participação das mulheres na política (SACCHET; SPECK, 2012).

Assim, torna-se imprescindível o reconhecimento de que a sociedade deve ser constituída por várias representações e que abarque diferentes opiniões e ideias por meio da multiplicidade de gêneros em todos os centros de poder.

Nesse sentido, vale ressaltar que o exercício dos direitos individuais e sociais se consagram a partir do momento em que todos participam do processo político de uma nação, com as mesmas oportunidades e a mesma igualdade nas garantias econômicas, e isso inclui a distribuição de recursos em mesmo patamar entre mulheres e homens.

Conforme observado, o terreno econômico é onde mais se cogita o uso abusivo de poder nas eleições, o que acarreta grave desequilíbrio da disputa. Por isso, o legislador intervém, conferindo equilíbrio ao certame. Quer-se impedir que a riqueza dos mais abastados interfira de forma decisiva no resultado das eleições. Com isso, também se cumpre o princípio constitucional da isonomia, pois, se todos são iguais perante a lei, justo não seria que houvesse grande diferença de oportunidades para a ocupação de cargos político eletivos (GOMES, 2012).

Dessa forma, pode-se perceber que os recursos financeiros possuem uma grande 
relevância nas competições eleitorais, na medida em que eles viabilizam as candidaturas e podem aumentar as chances de sucesso nas urnas, uma vez que a lógica econômica nas eleições indica que quem investe mais, consequentemente, possui mais facilidade de obter o objetivo pretendido, o voto.

\section{MULHERES EM LUTA PELA REPRESENTAÇÃO POLÍTICA}

Ainda que se entenda que a igualdade política entre homens e mulheres não se inicia, nem se esgota nas eleições e nos acessos aos cargos públicos, sabe-se que este é o caminho pelo qual as mulheres podem aumentar seu poder de pressão (MELO, 2018).

Nos últimos anos, atendendo à pressão do movimento de mulheres brasileiras, setores do legislativo (em especial a bancada feminina no Congresso Nacional) e do executivo têm demonstrado certa preocupação em criar mecanismos que possam ampliar a representação feminina nas estruturas do poder no país.

Tais preocupações se configuram no estabelecimento de um sistema de cotas políticas e uma série de ações no campo das políticas públicas, respaldadas principalmente no II Plano Nacional de Políticas para Mulheres.

Em 1995, o Congresso aprovou a lei 9.100, chamada Lei de Cotas, apresentada pela Deputada Marta Suplicy (PT-SP) atendendo uma articulação de mulheres parlamentares do MERCOSUL. A lei estipulava uma cota de $20 \%$ para mulheres.

A Lei 9.504 aumentou a cota para 25\% nas eleições de 1998, e 30\% para as eleições posteriores. Entretanto, esse sistema de cotas para as mulheres aprovado no Brasil se apresentou insuficiente, no sentido de que não contemplava nenhum mecanismo que pudesse garantir a obrigatoriedade dos partidos políticos.

Em 2009, foi sancionada a Lei 12.034/09 que diz respeito a legislação eleitoral. A partir dessa lei, os partidos são obrigados a destinar $5 \%$ do fundo partidário à formação política das mulheres, e $10 \%$ do tempo de propaganda partidária utilizada para promover e difundir a participação das mulheres na política.

De acordo com essa lei, os partidos que não cumprirem a regra dos $5 \%$, deverão acrescentar mais $2,5 \%$ dos recursos do fundo partidário no ano em ações de formação feminina.

No $5^{\circ}$ Capítulo do II Plano Nacional de Políticas Públicas, define como objetivo geral: "Promover e fortalecer a participação igualitária, plural e multirracial" e apresenta como um dos seus objetivos específicos: "Inserir no debate da reforma política o tema da paridade na representação parlamentar" (SPM, 2008, 119).

Hoje, apesar da existência da lei de cotas que determina que pelo menos $30 \%$ das candidatas representadas pelos partidos sejam mulheres, estudos têm mostrado que eles têm tratado essa obrigatoriedade apenas de forma burocrática. Para conseguir o número mínimo e não serem punidos, os partidos acabam recrutando candidatas laranjas ou "fantasmas", já que há casos em que elas nem sabem da existência de seus 
nomes na lista.

Há também um preconceito impresso na sociedade e principalmente no conjunto de regras e normas do sistema eleitoral, que favorece e preserva a maioria masculina nos espaços de poder político, pois não há estímulo à inclusão feminina nas administrações públicas e na competição eleitoral, essa diferença começa até mesmo nos diretórios dos partidos, que em sua maioria são constituídos por homens.

A partir disso, vamos observar algumas variáveis para tão baixa efetividade de representação feminina como o processo de recrutamento e apoio às mulheres: os partidos políticos são canal de participação da sociedade para que se possa alcançar o poder através da disputa eleitoral, e o partido político está presente dentre os primeiros trâmites para viabilizar as candidaturas. Contudo, os partidos políticos em sua maioria, não se atentam em agir de forma justa e igualitária na seleção de candidatos e distribuição de recursos para eleições (RAMOS, 2015).

Segundo Ramos (2015), o Sistema eleitoral Brasileiro, por ser um sistema majoritário e proporcional de lista aberta, acaba não contribuindo e viabilizando de forma justa a eleição das mulheres. Ainda que o sistema proporcional favoreça a ascensão política de mulheres e grupo minoritários, o problema se concentra também na lista aberta, em virtude de que cada candidato compete individualmente pelos votos, tornando mais difícil aos candidatos com menos recursos financeiros e políticos obter sucesso no desempenho eleitoral, porque não há um pré-ordenamento dos candidatos na lista.

Dessa maneira, como elas não recebem fundo partidário, consequentemente, não desenvolvem nenhuma campanha real com expectativa de se elegerem. Não é à toa que, em 2012, as mulheres foram $86 \%$ das candidatas que não tiveram nenhum voto, ou seja, nem elas votaram nelas mesmas.

Há quem defenda que é preciso não somente cotas para o número de candidatas, mas também para o número de cadeiras, como é o caso de países como o Uruguai e Argentina. Nesses países, foram definidas cotas para as eleitas, e não para o número de candidatas, isso resultou num salto muito grande em termos de representação.

Entretanto, no Brasil, há resistência política quanto essas cotas. Muitos consideram que essas medidas não funcionam e que o ideal seria apenas punir os partidos que tiveram candidatas "laranjas" e que não repassaram os recursos financeiros paras as campanhas das mulheres.

Desde 2015, importantes medidas foram aprovadas em favor do financiamento das mulheres, em destaque a provação do piso mínimo do fundo especial de financiamento de campanha e a definição do percentual mínimo a ser seguido para a distribuição do horário eleitoral gratuito no rádio e tv.

Mesmo com essas conquistas, reconhece-se que há muitas barreiras a serem superadas, desafios estes que vão desde o momento inicial com o recrutamento das candidatas até o ápice das eleições. E nesse processo, o dinheiro passa a ter grande relevância. 


\section{LEGISLAÇÃO ELEITORAL: NORMATIZAÇÃO E PRERROGATIVAS ÀS CAMPANHAS DAS MULHERES.}

O financiamento eleitoral é normatizado pela Lei 9.504/97, conhecida como Lei das Eleições, e pela Lei 9.096/96, designada como a Lei Orgânica dos Partidos Políticos, que clarifica desde a prestação de contas dos partidos até o Fundo Partidário.

A Lei das Eleições regulamenta todos os pleitos eleitorais, no qual a arrecadação de recursos para o pleito é realizada pelos partidos ou diretamente pelos candidatos (ARAÚJO, 2005).

Entendendo que o objetivo do financiamento é arcar com as despesas das campanhas eleitorais, o artigo 26 da Lei 9.504/97, dada a redação da lei 11.300/2006, compreende como gastos eleitorais:

I - confecção de material impresso de qualquer natureza e tamanho, observado o disposto no § 30 do art. 38 desta Lei; (Redação dada pela Lei $n^{\circ} 12.891$, de 2013) II - propaganda e publicidade direta ou indireta, por qualquer meio de divulgação, destinada a conquistar votos;

III - aluguel de locais para a promoção de atos de campanha eleitoral;

IV - despesas com transporte ou deslocamento de candidato e de pessoal a serviço das candidaturas; (Redação dada pela Lei $n^{\circ} 11.300$, de 2006)

$V$ - correspondência e despesas postais;

VI - despesas de instalação, organização e funcionamento de Comitês e serviços necessários às eleições;

VII - remuneração ou gratificação de qualquer espécie a pessoal que preste serviços às candidaturas ou aos comitês eleitorais;

VIII - montagem e operação de carros de som, de propaganda e assemelhados;

IX - a realização de comícios ou eventos destinados à promoção de candidatura;

(Redação dada pela Lei $n^{\circ} 11.300$, de 2006)

$X$ - produção de programas de rádio, televisão ou vídeo, inclusive os destinados à propaganda gratuita;

XI - (Revogado pela Lei $n^{\circ} 11.300$, de 2006)

XII - realização de pesquisas ou testes pré-eleitorais;

XIII - (Revogado pela Lei $n^{\circ} 11.300$, de 2006)

XIV - (revogado); (Redação dada pela Lei no 12.891, de 2013)

$X V$ - custos com a criação e inclusão de sítios na Internet;

$\mathrm{XVI}$ - multas aplicadas aos partidos ou candidatos por infração do disposto na legislação eleitoral.

XVII - produção de jingles, vinhetas e slogans para propaganda eleitoral. (Incluído pela Lei $n^{\circ} 11.300$, de 2006) (BRASIL, 1997).

Vale ressaltar que para os partidos políticos arrecadarem os recursos necessário para o custeio dos seus gastos, a Lei n 9.504/97 exige a obrigatoriedade da criação de comitês financeiros com a finalidade de administrar os recursos angariados, sendo um comitê para cada eleição a qual o partido pretenda apresentar candidatura própria. Já no caso dos candidatos, estes estão autorizados a arrecadar por conta própria ou por meio de uma pessoa por ele designada para administrar a parte financeira e sua campanha (SILVA; XAVIER, 2015).

No Brasil, as formas de financiamento de campanha podem ser classificadas 
como: financiamento público e financiamento privado. Esses recursos podem ser advindos por meio de pessoa física, recursos partidários, recursos próprios e através dos recursos do Fundo Especial de Assistência Financeira aos Partidos Políticos, também conhecido como fundo partidário, este último pode ser utilizado tanto para financiar candidatos, como ainda beneficiar os comitês financeiros.

Fazer uma campanha eleitoral tem um alto custo. Só em 2014, R\$ 5 bilhões foram declarados. A maior quantia já gasta na história. Até esta eleição de 2014, as empresas podiam doar aos candidatos e respondia por quase tudo o que era arrecadado nas campanhas.

A partir das eleições de 2016, novas regras foram admitidas, em razão da minirreforma eleitoral, com a Lei $n^{\circ} 13.165$, de 29 de setembro de 2015 que altera as Leis $n^{\circ}$ 9.504, de 30 de setembro de 1997, 9.096, de 19 de setembro de 1995, e 4.737, de 15 de julho de 1965 do Código Eleitoral, tal mudança surgiu no intuito de reduzir os custos das campanhas eleitorais, simplificar a administração dos partidos políticos e incentivar a participação feminina.

As novas fontes de receita foram revistas, sendo definido quatro principais regras: A primeira regra é com relação ao teto dos gastos. Os valores de campanha não podem ultrapassar os valores determinados pela justiça eleitoral.

Para presidente, o limite é de 70 milhões no $1^{\circ}$ turno e $R \$ 105$ no $2^{\circ}$ turno, se houver. Para governador, 21 milhões no $1^{\circ}$ turno e 31,5 milhões no $2^{\circ}$ turno, de acordo com o número de eleitores do estado. Para senador, $\mathrm{R}$ \$ 2,5 milhões a 5,6 milhões de acordo com o número de eleitores do estado. Para deputado federal, $R \$ 2,5$ milhões e 1 milhão para Deputado federal / Distrital.

A segunda regra é o fundo eleitoral. Foi criado pelos parlamentares para compensar a falta de dinheiro das empresas. Nessa situação, os partidos só podem receber o fundo a partir do momento que já estiver definido com a executiva nacional como irá distribuir o recurso entre seus candidatos, e isso deve ser publicado em diário oficial.

A orientação que se tem é de que nenhuma mudança ocorra posteriormente à divisão do recurso, no entanto, não é mencionada a proibição quanto a isso na nova legislação. O que pode dar margem para os partidos distribuírem desigualmente o dinheiro e privilegiarem mais os homens.

A terceira regra é o autofinanciamento. O candidato pode doar seu próprio dinheiro para custear sua campanha. Essa regra entrou em vigor desde 2016. Nesse caso, quem se beneficia são os candidatos com maior poder aquisitivo, porque eles podem doar quanto puderem para tentar uma legislatura.

$\mathrm{E}$ a quarta regra diz respeito às doações de pessoas físicas. Partidos e candidatos podem utilizar recursos doados por pessoas físicas. Cada eleitor pode doar até 10\% dos rendimentos brutos declarados no ano anterior às eleições.

Um dos aspectos positivos que devem ser ressaltados nessa minirreforma diz respeito ao estímulo à Participação Feminina, pois evidenciou-se a criação e manutenção de programas de promoção e difusão da participação política das mulheres, criados e mantidos pela secretaria da mulher do respectivo partido político ou pelo instituto ou fundação de pesquisa de doutrinação e educação política. 
Outro ponto positivo da Lei $n^{0} 13.165 / 2015$ que trouxe mudanças significativas ao processo das candidaturas femininas, foi a proibição de propaganda através de placa, faixas e cavaletes e a redução do tempo de campanha de noventa dias para quarenta e cinco dias.

Ficou determinado ainda o cumprimento do horário eleitoral de 5 min diários entre 01 abril e 30 julho no ano eleitoral, $10 \%$ do tempo da inserção de partidos reservado às mulheres e a destinação de $5 \%$ a $15 \%$ do recurso do fundo partidário às candidatadas.

Para incentivar as doações de pessoas físicas, uma das práticas de doações pouco conhecidas no Brasil foi regulamentada pela justiça eleitoral, através do uso de ferramentas de financiamento coletivas conhecidas como vaquinhas virtuais. Essa realidade permite às candidatas a possibilidades de se conectarem a redes de contatos e grupos influentes que oferecem financiamento de campanha e apoio à defesa dos direitos políticos das mulheres.

Cada eleitor pode doar até R\$1.000,00 por dia. Quem quiser doar mais, tem que fazer uma transferência para a conta do partido ou candidato. É permitido doar para mais de um candidato, desde que não ultrapasse o limite de $10 \%$ do rendimento.

A doação precisa ser identificada através do fornecimento de dados com o nome completo e CPF. Todas essas informações, incluído o valor da doação, deve constar na prestação de contas dos candidatos. Desse modo, todo dinheiro que circula uma campanha precisa ser declarado à justiça eleitoral, que verifica eventuais distorções entre o que entra e o que sai da conta dos candidatos.

Informações não declaradas, como o uso do caixa dois, são proibidas e punidas na forma da lei. Os doadores podem ser condenados a pagar uma multa no valor de 5 a 10 vezes a quantia que foi doada irregular e as legendas podem ficar sem uma parte do fundo partidário. Quanto ao candidato que for pego recebendo dinheiro indevido, poderá ter seu registro cassado e ainda ficará inelegível nos oito anos posteriores.

No entanto, irregularidades são constantemente denunciadas em meio às eleições sobre a comprovação de caixa dois, evidenciando que a corrupção e a violação às leis eleitorais são difíceis de serem banidas do cenário político brasileiro. Consequentemente, essas lacunas, podem possibilitar a influência do poder econômico nas eleições, proporcionando desigualdade entre mulheres e homens.

\section{RESULTADOS E DISCUSSÃO}

Ao analisar as diferenças na arrecadação de recursos nas campanhas de mulheres e homens eleitos em relação ao cargo em disputa, percebeu-se que as mulheres arrecadaram um volume de recursos significativamente inferior aos homens, para os cargos de deputado federal, deputado estadual e vereador em disputa nas eleições 2014 e 2016, ou seja, independente do cargo em disputa as mulheres são subfinanciadas.

A tabela 1 mostra que, para deputado(a) estadual, as mulheres receberam em média $R \$ 21.216,61$, enquanto que os homens $R \$ 42.518,69$, essa diferença evidencia o 
alto grau de desigualdade entre homens e mulheres, pois eles receberam praticamente o dobro das candidatas. Para os cargos de deputado (a) federal, a diferença na arrecadação de recursos foi ainda mais dispare. As mulheres receberam em média $\mathrm{R} \$ 34.417,18$, enquanto que os homens receberam $\mathrm{R} \$ 94.922,11$ uma diferença de $175,8 \%$ homens receberam $\mathrm{R} \$ 94.922,11$ uma diferença de 175,8\%. Somente para os cargos de vereador, essa diferença foi menor, onde as mulheres arrecadaram em média 1.094,91 e os homens mantiveram uma média de 1.843,75, mais ainda assim, a diferença foi de mais de $68,39 \%$.

Para Speck (2012), o sucesso na política está diretamente ligado em múltiplos sentidos ao dinheiro, pois é ele um item essencial na mobilização das estratégias de campanha e um dos principais objetos da política, seja qual for o cargo disputado.

Tabela 1 - Receita média recebida pelos candidatos aos cargos de deputado federal, estadual e vereador nas eleições 2014 e 2016, segundo o sexo do candidato

\begin{tabular}{|c|c|c|c|c|c|c|c|}
\hline \multirow{3}{*}{ Cargo } & \multicolumn{6}{|c|}{ Sexo } & \multirow{3}{*}{ P-Valor ${ }^{(1)}$} \\
\hline & \multicolumn{3}{|c|}{ Feminino } & \multicolumn{3}{|c|}{ Masculino } & \\
\hline & $\mathbf{N}$ & Média (R\$) & $\begin{array}{c}\text { Desvio } \\
\text { Padrão (R\$) } \\
\end{array}$ & $\mathbf{N}$ & Média (R\$) & $\begin{array}{c}\text { Desvio } \\
\text { Padrão (R\$) } \\
\end{array}$ & \\
\hline Deputado Estadual & 7.663 & $21.216,61$ & $88.137,70$ & 25.106 & $42.518,69$ & $129.082,01$ & $0.000^{*}$ \\
\hline Deputado Federal & 3.324 & $34.417,18$ & $180.548,43$ & 11.158 & $94.922,11$ & $295.885,45$ & $0.000^{*}$ \\
\hline Vereador & 88.325 & $1.094,91$ & $4.598,38$ & 209.706 & $1.843,75$ & $87.499,34$ & $0.011^{*}$ \\
\hline
\end{tabular}

(1) Teste $t$ de Student para comparação de médias ( $p$-valor<0.05).

*Valores Significativos; NS Valores Não Significativos.

Interpretação do teste:

HO: As médias observadas não diferem significativamente entre homens e mulheres para os diferentes cargos.

$\mathrm{Ha}$ : As médias observadas diferem significativamente entre homens e mulheres para os diferentes cargos.

Decisão: Como o valor de p computado é menor que o nível de significância alfa $=0,05$, deve-se rejeitar a hipótese nula $\mathrm{H} 0$ e aceitar a hipótese alternativa $\mathrm{Ha}$.

Fonte: Dados colEstados no TSE (2018)

Ao avaliar as diferenças na distribuição dos recursos financeiros às candidaturas de mulheres e homens em relação à ideologia partidária, percebeu-se que em todos os partidos a receita média recebida pelos candidatos masculinos foi superior ao recebido pelas mulheres.

Verifica-se na tabela 2 que para todos os partidos a receita média recebida pelos candidatos masculinos é superior ao recebido pelas mulheres, com destaque para os partidos PT (VM = 14.156), PSDB (VM = 10.098) e PMDB (VM=9,814) que apresentaram as maiores diferenças da receita média.

Dessa forma, foi possível constatar que, sem exceção, os partidos políticos oferecem baixa oferta de recursos para financiar as campanhas das mulheres quando comparamos esse valor ao financiamento oferecido aos homens, e essa diferença se perpetua em todos os cargos disputados. Para Araújo (2005, p. 31), "o grau e o tipo de organização interna de cada partido são vistos como fundamentais para facilitar a inserção das mulheres e criar condições de competição". Desse modo, o papel dos partidos torna-se preponderante nesse processo. 
Tabela 2 - Comparação da receita média recebida pelos candidatos aos cargos de deputado federal, estadual e vereador nas eleições 2014 e 2016, segundo o sexo do candidato e o partido político

\begin{tabular}{|c|c|c|c|c|c|c|c|}
\hline \multirow{3}{*}{$\begin{array}{l}\text { Partido } \\
\text { Político }\end{array}$} & \multicolumn{6}{|c|}{ Sexo } & \multirow{3}{*}{$\begin{array}{l}\text { Variação } \\
\text { Média (R\$) }\end{array}$} \\
\hline & \multicolumn{3}{|c|}{ Feminino } & \multicolumn{3}{|c|}{ Masculino } & \\
\hline & $\mathbf{n}$ & Média & Desvio Padrão & $\mathbf{N}$ & Média & Desvio Padrão & \\
\hline PT & 5,714 & 9611.27 & 59397.54 & 12,405 & 23767.32 & 116605.63 & 14,156 \\
\hline PSDB & 7,898 & 4265.45 & 35087.83 & 18,961 & 14363.31 & 108382.55 & 10,098 \\
\hline PMDB & 10,119 & 4019.31 & 36751.72 & 23,754 & 13833.44 & 103108.50 & 9,814 \\
\hline PSD & 5,518 & 3061.39 & 31240.20 & 14,144 & 12767.88 & 97449.75 & 9,706 \\
\hline DEM & 4,321 & 2772.32 & 40939.60 & 10,682 & 11133.41 & 90822.90 & 8,361 \\
\hline SD & 2,661 & 2739.91 & 28792.71 & 7,255 & 11064.51 & 83446.39 & 8,325 \\
\hline PSB & 5,311 & 4524.83 & 51725.14 & 14,158 & 11958.41 & 340907.19 & 7,434 \\
\hline PP & 6,25 & 4059.95 & 71333.94 & 14,821 & 11191.95 & 97135.35 & 7,132 \\
\hline PROS & 1,759 & 2979.78 & 20926.90 & 4,82 & 9956.41 & 61664.92 & 6,977 \\
\hline PR & 4,44 & 4755.55 & 54010.26 & 11,148 & 10430.42 & 84977.37 & 5,675 \\
\hline PSL & 1,916 & 2093.69 & 11337.53 & 4,881 & 7341.34 & 61451.93 & 5,248 \\
\hline PV & 3,85 & 1913.30 & 10435.35 & 9,439 & 6595.77 & 49283.44 & 4,682 \\
\hline PDT & 5,457 & 3254.15 & 23446.19 & 13,377 & 7851.68 & 49709.91 & 4,598 \\
\hline РTB & 5,081 & 3607.06 & 75929.31 & 12,624 & 8106.86 & 78583.53 & 4,5 \\
\hline PMN & 1,255 & 2138.50 & 15072.29 & 3,09 & 6553.75 & 68603.05 & 4,415 \\
\hline PPS & 3,46 & 2608.87 & 19878.69 & 8,819 & 6842.24 & 69382.11 & 4,233 \\
\hline PT do B & 1,317 & 3235.74 & 24124.91 & 3,574 & 7354.60 & 47379.26 & 4,119 \\
\hline PEN & 1,754 & 1331.92 & 6745.49 & 4,892 & 5337.60 & 37020.66 & 4,006 \\
\hline$P C$ do $B$ & 2,198 & 7709.49 & 53610.18 & 5,55 & 11135.33 & 80212.11 & 3,426 \\
\hline NOVO & 66 & 5559.35 & 18669.14 & 128 & 8904.46 & 32392.05 & 3,345 \\
\hline PHS & 2,043 & 1358.56 & 4606.50 & 5,508 & 4594.45 & 28954.06 & 3,236 \\
\hline PRB & 3,416 & 2594.79 & 18303.21 & 8,273 & 5542.78 & 40615.63 & 2,948 \\
\hline PSDC & 1,446 & 1610.89 & 11374.74 & 3,616 & 4541.25 & 22233.02 & 2,93 \\
\hline PPL & 568 & 2130.19 & 8745.88 & 1,482 & 4729.08 & 34026.04 & 2,599 \\
\hline PRP & 1,525 & 2701.08 & 29865.28 & 4,012 & 5287.71 & 23936.93 & 2,587 \\
\hline PSC & 3,108 & 4495.08 & 51169.21 & 8,075 & 6995.05 & 55563.20 & 2,5 \\
\hline PRTB & 1,034 & 1785.00 & 15024.31 & 2,835 & 3864.37 & 16154.02 & 2,079 \\
\hline PTN & 1,876 & 3079.53 & 37522.04 & 4,685 & 4756.48 & 25840.21 & 1,677 \\
\hline РTC & 1,473 & 2981.51 & 34166.05 & 3,876 & 4422.45 & 24645.45 & 1,441 \\
\hline PSOL & 868 & 2575.73 & 7901.93 & 2,251 & 3926.83 & 14088.32 & 1,351 \\
\hline REDE & 570 & 910.91 & 1673.57 & 1,365 & 2021.79 & 10891.08 & 1,111 \\
\hline PCB & 34 & 1046.34 & 1161.96 & 84 & 1526.04 & 2226.16 & 480 \\
\hline PMB & 843 & 1174.82 & 3855.20 & 1,111 & 1601.79 & 5182.14 & 427 \\
\hline PSTU & 152 & 2194.52 & 5120.28 & 251 & 2594.80 & 6196.26 & 400 \\
\hline PCO & 11 & 773.35 & 802.28 & 24 & 820.47 & 309.30 & 47 \\
\hline
\end{tabular}

Fonte: Dados resultantes da pesquisa (2018)

Seguindo as análises, ao organizar os dados por ordem de classificação considerando os partidos de direta, esquerda e centro e respectivas receitas dos candidatos, observou-se que entre as três ideologias, os partidos de esquerda foram os que apresen- 
taram menor diferença na proporção de financiamento entre as mulheres e os homens, ou seja, mesmo que as mulheres sejam subfinanciadas em todos os partidos em relação aos homens, os partidos de esquerda são os que ainda ofereceram maiores condições de financiamento através do fundo partidário em relação às mulheres eleitas provindas dos partidos de centro e direita.

Observando abaixo, um dado que chama a atenção na tabela 3 , é que nas três ideologias partidárias a receita média recebida pelos candidatos masculinos é significativamente $(p<0.05)$ superior ao recebido pelas mulheres, com destaque para a ideologia de esquerda, onde as mulheres obtiveram receita média igual a $R \$ 4.741,53$, enquanto que os homens obtiveram receita média igual a $\mathrm{R} \$ 11.415,38$.

Outro estudo realizado por Gomes (2016) através de uma amostra com 81 candidatas à Assembleia Legislativa de Minas Gerais em 2010, indicou que as mulheres têm dificuldades em conseguir apoio partidário independente da ideologia do partido. Enquanto a esquerda apresentou uma pequena preponderância na abertura de espaços partidários e no conhecimento sobre as causas da sub-representação feminina, seu apoio às mulheres em tempos de campanha não difere dos outros campos ideológicos, apesar dos esforços para aumentar a presença das mulheres nesses cargos na forma de cotas internas.

Tabela 3 - Comparação da receita média recebida pelos candidatos aos cargos de deputado federal, estadual e vereador nas eleições 2014 e 2016, segundo o sexo do candidato e a ideologia partidária

\begin{tabular}{|c|c|c|c|c|c|c|c|}
\hline \multirow{3}{*}{ Cargo } & \multicolumn{6}{|c|}{ Sexo } & \multirow{3}{*}{ P-Valor ${ }^{(1)}$} \\
\hline & \multicolumn{3}{|c|}{ Feminino } & \multicolumn{3}{|c|}{ Masculino } & \\
\hline & $\mathbf{N}$ & Média & $\begin{array}{l}\text { Desvio } \\
\text { Padrão }\end{array}$ & $\mathbf{N}$ & Média & $\begin{array}{l}\text { Desvio } \\
\text { Padrão }\end{array}$ & \\
\hline Centro & 35,54 & 3557,74 & 41099,28 & 87,316 & 11686,34 & 91905,97 & $0.000^{*}$ \\
\hline Direita & 34,67 & 3151,5 & 44237,19 & 87,432 & 7775,51 & 66606,99 & $0.000^{*}$ \\
\hline Esquerda & 29,1 & 4741,53 & 40562,18 & 71,222 & 11415,38 & 167380,42 & $0.000^{*}$ \\
\hline
\end{tabular}

(1) Teste t de Student para comparação de médias ( $p$-valor<0.05).

*Valores Significativos; NS Valores Não Significativos.

Interpretação do teste:

H0: As médias observadas não diferem significativamente entre homens e mulheres para as diferentes ideologias.

Ha: As médias observadas diferem significativamente entre homens e mulheres para as diferentes ideologias.

Decisão: Como o valor de $\mathrm{p}$ computado é menor que o nível de significância alfa $=0,05$, deve-se rejeitar a hipótese nula H0 e aceitar a hipótese alternativa $\mathrm{Ha}$

E por último, ao analisar as alterações nas fontes de financiamento das mulheres e dos homens eleitos em relação aos estados da federação sob o qual representam, verificou-se que em todas as regiões brasileiras as mulheres obtiveram uma receita média inferior aos homens.

Do ponto de vista geográfico, percebeu-se a ocorrência de diferenças significativas nos padrões de financiamento de campanhas das mulheres entre os estados e regiões do Brasil.

De acordo com a tabela 4, na região Centro-Oeste, as candidatas ao cargo de deputada federal obtiveram maior arrecadação média ( $\mathrm{R} \$ 63.363,56)$, contudo a receita média arrecadada pelos candidatos do sexo masculino, para o mesmo cargo, foi significativamente superior, o equivalente a $(R \$ 143.483,50)$. 
Na região Nordeste, as candidatas ao cargo de deputada federal também obtiveram maior arrecadação média ( $R$ \$ 42.849,41), contudo, a receita média arrecadada pelos candidatos do sexo masculino, para o mesmo cargo, foi significativamente superior ( $R \$$ 105.657,75). O mesmo comportamento foi observado para as demais regiões brasileiras.

Dessa forma, considerando o âmbito das relações partidárias de poder, no território brasileiro, observa-se que apesar da existência de leis que garantem a igualdade de oportunidade entre homens e mulheres nas eleições, as análises apontam a presença de barreiras na representação entre candidatos e a desvantagem no acesso aos recursos políticos partidários (MIGUEL e BIROLI, 2011; SPECK e SACCHET, 2012).

Tabela 4 - Comparação da receita média recebida pelos candidatos aos cargos de deputado federal, estadual e vereador nas eleições 2014 e 2016, segundo o sexo do candidato, região e cargo

\begin{tabular}{|c|c|c|c|c|c|c|c|c|}
\hline \multirow{3}{*}{ Região } & \multirow{3}{*}{ Cargo } & \multicolumn{3}{|c|}{ Feminino } & \multicolumn{3}{|c|}{ Masculino } & \multirow{3}{*}{ P-Valor } \\
\hline & & \multirow{2}{*}{$\mathbf{N}$} & \multirow{2}{*}{ Média } & \multirow{2}{*}{$\begin{array}{l}\text { Desvio } \\
\text { Padrão }\end{array}$} & \multirow{2}{*}{$\mathbf{N}$} & \multirow{2}{*}{ Média } & \multirow{2}{*}{$\frac{\text { Desvio }}{\text { Padrão }}$} & \\
\hline & & & & & & & & \\
\hline \multirow{3}{*}{$\begin{array}{c}\text { Centro- } \\
\text { Oeste }\end{array}$} & Deputado Estadual & 697 & $31.014,09$ & $115.546,65$ & 2.217 & $69.845,73$ & $179.276,61$ & $<0.0001^{*}$ \\
\hline & Deputado Federal & 283 & $63.363,56$ & $266.120,07$ & 843 & $143.483,50$ & $330.706,39$ & \\
\hline & Vereador & 7215 & $1.482,38$ & $4.001,68$ & 17.042 & $2.000,00$ & $4.733,48$ & \\
\hline \multirow{3}{*}{ Nordeste } & Deputado Estadual & 1381 & $24.074,69$ & $85.664,17$ & 5.070 & $38.912,03$ & $86.931,15$ & $<0.0001^{*}$ \\
\hline & Deputado Federal & 516 & $42.849,41$ & $253.611,10$ & 2.210 & $105.657,75$ & $304.616,27$ & \\
\hline & Vereador & 14165 & $1.313,47$ & $5.960,33$ & 36.563 & 1773,38 & $3.874,10$ & \\
\hline \multirow{3}{*}{ Norte } & Deputado Estadual & 1572 & $13.300,90$ & $38.675,45$ & 4.918 & $22.602,16$ & $60.052,94$ & $<0.0001^{*}$ \\
\hline & Deputado Federal & 421 & $41.735,06$ & $98.004,11$ & 1.158 & $70.858,41$ & $218.081,92$ & \\
\hline & Vereador & 6414 & $1.353,15$ & $2.630,95$ & 15.594 & $1.939,81$ & $4.486,66$ & \\
\hline \multirow{3}{*}{ Sudeste } & Deputado Estadual & 3007 & $22.287,63$ & $105.643,67$ & 9.307 & $49.085,59$ & $163.955,28$ & $<0.0001^{*}$ \\
\hline & Deputado Federal & 1671 & $28.446,04$ & $170.916,00$ & 5.531 & $85.893,67$ & $302.007,23$ & \\
\hline & Vereador & 39873 & 899,63 & $5.206,27$ & 96.019 & 1982,49 & $129.242,52$ & \\
\hline \multirow{3}{*}{ Sul } & Deputado Estadual & 1006 & $19.672,99$ & $63.245,48$ & 3.594 & $40.997,52$ & $101.206,84$ & $<0.0001^{*}$ \\
\hline & Deputado Federal & 433 & $21.378,13$ & $67.681,84$ & 1.416 & $104.201,10$ & $287.327,33$ & \\
\hline & Vereador & 20658 & $1.106,44$ & $2.410,96$ & 44.488 & $1.508,59$ & $3.104,20$ & \\
\hline
\end{tabular}

(1) Teste t de Student para comparação de médias (p-valor<0.05).

*Valores Significativos; NS Valores Não Significativos.

Interpretação do teste:

HO: As médias observadas não diferem significativamente entre homens e mulheres para os diferentes cargos.

Ha: As médias observadas diferem significativamente entre homens e mulheres para os diferentes cargos.

Decisão: Como o valor de $p$ computado é menor que o nível de significância alfa $=0,05$, deve-se rejeitar a hipótese nula H0 e aceitar a hipótese alternativa Ha.

E com relação às fontes de recursos, a pesquisa indicou que as médias observadas diferem significativamente entre candidatas e candidatos, independente das regiões do país, demonstrando, assim, que elas investem bem mais os próprios recursos e são as que menos recebem investimento de pessoa física quando comparado aos homens.

A tabela 5 mostra que em todas as regiões as mulheres apresentaram receita média menor que os homens. Na região Centro-Oeste, a receita média em relação à fonte de recur- 
sos próprios foi maior entre as mulheres, enquanto que para os homens candidatos dessa região, as receitas médias de recursos de pessoas físicas ( $\mu=R \$ 11.922,78)$ e recursos próprios ( $\mu=R \$ 11780,52)$ foram semelhantes.

Na região Nordeste, tanto os candidatos do sexo feminino ( $\mu=\mathrm{R} \$ 3.175,73)$ como do masculino ( $\mu=R \$ 6.043,67$ ), apresentaram receita média superior de fontes de pessoas físicas.

Na região Norte, tanto os candidatos do sexo feminino ( $\mu=\mathrm{R} \$ 4.965,95)$ como do masculino ( $\mu=\mathrm{R} \$ 8.986,28)$, apresentaram receita média superior de fontes de recursos próprios.

Na região Sudeste, as candidatas do sexo feminino $(\mu=R \$ 2.526,62)$ obtiveram maior receita média de fonte de pessoas físicas, enquanto que os candidatos do sexo masculino obtiveram maior arrecadação média de fontes de recursos próprios $(\mu=R \$ 7.212,98)$, apresentaram receita média superior de fontes de recursos próprios.

Na região Sul, as candidatas do sexo feminino ( $\mu=\mathrm{R} \$ 2.190,81)$ obtiveram maior receita média de fonte de recursos de pessoas físicas, enquanto que os candidatos do sexo masculino obtiveram maior arrecadação média de fontes de recursos próprios $(\mu=\mathrm{R} \$$ $7.212,98)$, apresentaram receita média superior de fontes de recursos próprios.

Os resultados desta pesquisa corroboram com os achados de Eduardo (2014), a distribuição dos recursos sempre esteve concentrada na candidatura dos homens, pois as evidências mostram que as receitas dos eleitos continuam muito superior às receitas das candidatas eleitas, e mostra que os aspectos relacionados à legislação do sistema político são insuficientes para superar as dificuldades enfrentadas pelas mulheres na luta por uma cadeira no parlamento.

Estabelecendo um paralelo com esta pesquisa, pode-se perceber que nas eleições de 2014 e 2016, as médias de receitas analisadas diferem significativamente entre homens e muIheres para as diferentes regiões do país em fontes de recursos, mostrando que elas investem menos os próprios recursos e têm menos incentivo das empresas em comparação aos homens.

Tabela 5 - Comparação da receita média recebida pelos candidatos aos cargos de deputado federal, estadual e vereador nas eleições 2014 e 2016, segundo o sexo do candidato, região e fonte de recurso

\begin{tabular}{|c|c|c|c|c|c|c|c|c|}
\hline \multirow{2}{*}{ Região } & \multirow{2}{*}{ Fonte de Recurso } & \multicolumn{3}{|c|}{ Feminino } & \multicolumn{3}{|c|}{ Masculino } & \multirow{2}{*}{ P-Valor } \\
\hline & & $\mathrm{N}$ & Média & Desvio Padrão & $\mathrm{n}$ & Média & Desvio Padrão & \\
\hline \multirow{2}{*}{$\begin{array}{l}\text { Centro- } \\
\text { Oeste }\end{array}$} & Recursos de pessoas físicas & 2819 & 4461,15 & 25413,7 & 6341 & 11922,78 & 71080,71 & \multirow{2}{*}{$<0.0001^{*}$} \\
\hline & Recursos próprios & 1663 & 6070,02 & 70473,12 & 5434 & 11780,52 & 87227,06 & \\
\hline \multirow{2}{*}{ Nordeste } & Recursos de pessoas físicas & 6719 & 3175,73 & 20990,93 & 16513 & 6043,67 & 26652,02 & \multirow{2}{*}{$<0.0001^{*}$} \\
\hline & Recursos próprios & 3760 & 2980,03 & 13382,35 & 13291 & 5996,3 & 28222,18 & \\
\hline \multirow{2}{*}{ Norte } & Recursos de pessoas físicas & 3336 & 4733,54 & 19047,67 & 7768 & 8560,24 & 32060,8 & \multirow{2}{*}{$<0.0001^{*}$} \\
\hline & Recursos próprios & 1451 & 4965,95 & 23115,06 & 4944 & 8986,28 & 40279,65 & \\
\hline \multirow{2}{*}{ Sudeste } & Recursos de pessoas físicas & 14160 & 2526,62 & 23035,17 & 32690 & 6184,68 & 33920,32 & \multirow{2}{*}{$<0.0001^{*}$} \\
\hline & Recursos próprios & 8178 & 2348,95 & 14139,4 & 28961 & 7212,98 & 240737,79 & \\
\hline \multirow{2}{*}{ Sul } & Recursos de pessoas físicas & 7761 & 2190,81 & 10869,43 & 15834 & 4318,48 & 21327,92 & \multirow{2}{*}{$<0.0001^{*}$} \\
\hline & Recursos próprios & 7027 & 1838,6 & 7615,6 & 17774 & 4487,55 & 36645,99 & \\
\hline
\end{tabular}

(1) Teste t de Student para comparação de médias ( $p$-valor<0.05).

*Valores Significativos; NS Valores Não Significativos.

Interpretação do teste:

H0: As médias observadas não diferem significativamente entre homens e mulheres para as diferentes regiões e fontes de recursos.

Ha: As médias observadas diferem significativamente entre homens e mulheres para as diferentes regiões e fontes de recursos.

Decisão: Como o valor de p computado é menor que o nível de significância alfa $=0,05$, deve-se rejeitar a hipótese nula H0 e aceitar a hipótese alternativa $\mathrm{Ha}$. 


\section{CONSIDERAÇÕES FINAIS}

Falar da representação feminina nos espaços de decisão política incide em discutir os fatores que obstaculizam sua chegada na conquista de um pleito. Desse modo, realizou-se esta pesquisa, sob o intuito de avaliar o padrão de financiamento das campanhas eleitorais das mulheres em relação aos homens para a Câmara dos Deputados, Assembleias Legislativas e Câmara de Vereadores nas eleições de 2014 e 2016, no Brasil. Dessa forma, este trabalho fundamentou-se nos dados da prestação de contas oferecida ao TSE durante o processo eleitoral.

Assim, pelos achados aqui expostos, chegou-se às seguintes conclusões: Ao analisar as diferenças na arrecadação de recursos nas campanhas de mulheres e homens eleitos em relação ao cargo em disputa, percebeu-se que as mulheres arrecadaram um volume de recursos significativamente inferior aos homens, para os cargos de deputado federal, deputado estadual e vereador em disputa nas eleições 2014 e 2016, ou seja, independente do cargo em disputa as mulheres são subfinanciadas.

Seguindo as análises, ao avaliar as diferenças na distribuição dos recursos financeiros às candidaturas de mulheres e homens em relação à ideologia partidária, percebeu-se que em todos os partidos a receita média recebida pelos candidatos masculinos foi superior ao recebido pelas mulheres.

Dessa forma, foi possível constatar que, sem exceção, os partidos políticos oferecem baixa oferta de recursos para financiar as campanhas das mulheres quando comparamos esse valor ao financiamento oferecido aos homens e essa diferença se perpetua em todos os cargos disputados.

No entanto, ao organizar os dados por ordem de classificação considerando os partidos de direta, esquerda e centro e respectivas receitas dos candidatos, observou-se que entre as três ideologias, os partidos de esquerda foram os que apresentaram menor diferença na proporção de financiamento entre as mulheres e os homens, ou seja, mesmo que as mulheres sejam subfinanciadas em todos os partidos em relação aos homens, os partidos de esquerda são os que ainda ofereceram maiores condições de financiamento através do fundo partidário em relação as mulheres eleitas provindas dos partidos de centro e direita.

E por último, ao analisar as alterações nas fontes de financiamento das mulheres e dos homens eleitos em relação aos estados da federação sob o qual representam, verificou-se que em todas as regiões brasileiras as mulheres obtiveram uma receita média inferior aos homens.

Do ponto de vista geográfico, percebeu-se a ocorrência de diferenças significativas nos padrões de financiamento de campanhas das mulheres as regiões do Brasil.

E com relação às fontes de recursos, a pesquisa indicou que as médias observadas diferem significativamente entre candidatas e candidatos na maioria nas regiões do país, demonstrando assim que elas investem bem mais os próprios recursos e são as que menos recebem investimento das empresas quando comparado aos homens.

Diante às análises e perspectivas abordadas ao longo da pesquisa, observa-se que 
os diferentes padrões utilizados no financiamento de campanha das mulheres dificultam a construção social de uma política representativa igualitária.

Por mais que a legislação eleitoral tenha apresentado importantes mudanças atra-

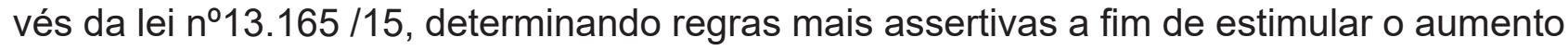
do número de candidatas ao longo das últimas eleições, verificou-se através dos achados deste trabalho que ainda há uma forte tendência à desigualdade na distribuição dos recursos e apoio político partidário para as candidaturas femininas, configurando tal realidade em uma séria situação de desvantagem em relação aos homens.

É bem perceptível que muitos foram os direitos conquistados através da luta das mulheres, mas ainda há um longo caminho a percorrer. Uma das perspectivas desta pesquisa foi chamar a atenção para questões problemas que envolvem o sistema de representação política brasileira e propiciar uma reflexão, a fim de que a sociedade, aliada aos seus representantes, possa cobrar um melhor parâmetro que favoreça a ampliação do número de mulheres nas esferas de poder, já que, o cenário atual apresentado nos evidencia profundas desigualdades nos padrões de financiamento nas campanhas eleitorais das mulheres nas eleições brasileiras.

Sendo assim, observou-se que os diferentes padrões utilizados no financiamento de campanha das mulheres dificultam a construção social e inclusiva de uma política representativa. Evidenciando que a democracia brasileira encontra-se longe de alcançar um patamar de igualdade política entre os gêneros.

\section{REFERÊNCIAS}

ARAÚJO, C. (2005). Partidos Políticos e Gênero: Mediação nas Rotas de Ingresso das Mulheres nas representações Políticas. Revista de Sociologia Política, Curitiba, n² 24, p. 193-215.

EDUARDO, M. C. (2017). Gênero financiado: uma análise da distribuição de recursos financeiros e o desempenho eleitoral das mulheres nas eleições de 2014. In: $41^{\circ}$ Encontro anual da ANPOCS, 2017, Caxambu. Anais do 41 encontro anual da ANPOCS.

FERNANDES L. A.; Gomes, J. M. M. (2009). Relatório de pesquisa nas Ciências Sociais. Porto Alegre: Contexto.

GOMES, L. (2016). Elegendo mulheres: ideologia, feminismo e inclusão de mulheres na política. Revista Eletrônica de Ciência Política, vol. 7, p. 35-53.

GOMES, J. J. (2012). Direito eleitoral. $8^{a}$ ed. São Paulo: Atlas.

RAMOS. L. (2017). Sub-representação feminina no Congresso afeta direitos sociais da mulher. São Paulo. 2015. Carta Capital - Entrevista concedida a Marcelo Pellegrini. Disponível em: https://www.cartacapital.com.br/politica/sub-representacao-feminina-no-congresso-afetadireitos-sociais-da-mulher-4112: Acesso: 23 de agosto de 2017 
MELO, H. P. de. (2018). Mulheres e poder: Histórias, ideias e indicadores. Rio de janeiro: FGV editora.

MIGUEL, L. F.; BIROLI, F. (2011). Práticas de gênero e carreiras políticas: vertentes explicativas. Revista Estudos Feministas, vol.18, n³, p. 653-679.

RODRIGUES, E. R. (2016). A mulher no parlamento brasileiro: trajetória político eleitoral e atuação parlamentar. Brasília. 78 f. Monografia (Bacharelado em Ciência Política). Universidade de Brasília.

SACCHET, T. (2009). Capital social, gênero e representação política no Brasil. Opinião Pública, Campinas, vol. 15, $\mathrm{n}^{\circ} .2$, p. 306-332.

SACCHET, T.; SPECK, B. W. (2011). Financiamento eleitoral, representação política e gênero: uma análise das eleições de 2006. São Paulo: Universidade de São Paulo.

SACCHET, T.; SPECK, B. (2012). Dinheiro e Sexo na Política Brasileira: financiamento de campanha e desempenho eleitoral em cargos legislativos. In: ALVES, J. E. D.; PINTO, C. R. J.; JORDÃO, F. (Org.). Mulheres nas eleições de 2010. São Paulo, ABCP.

SAMUELS, D. (2005). Financiamento de campanhas no Brasil e propostas de reforma. Suffragium - Revista do Tribunal Regional Eleitoral do Ceará, Fortaleza, vol. 1, n 1, p. 11-28.

SANTOS, R.; TANAKA, M. (2016). O financiamento partidário e o impacto na competição eleitoral. In: $40^{\circ}$ Encontro Anual da ANPOCS, 2018, Caxambu. Anais do $40^{\circ}$ encontro anual da ANPOCS.

SANTOS, R. D. dos. (2011). Grandes Empresários e Sucesso Eleitoral nas eleições de 2002, 2006 e 2010. In: $35^{\circ}$ Encontro Anual da Anpocs, 2011, Caxambu. Anais do $35^{\circ}$ encontro anual da ANPOCS.

SILVA, M.; XAVIER, A. (2015). O financiamento de campanha eleitoral e sua influência na representação. Brasília: Vestnik.

Recebido em 23/11/2019

Aprovado em 02/12/2019

SOBRE OS AUTORES

Valdenize Gurjão Corrêa é mestre em Ciência Política pela Universidade Federal do ParáPPGCP-UFPA. Lattes: http://lattes.cnpq.br/3926849029376358. E-mail: valdenizegurjao@ gmail.com.

Rodrigo Dolandeli dos Santos é doutor em Ciência Política e Professor do Programa de Pós-graduação em Ciência Política da Universidade Federal do Pará PPGCP- UFPA. Lattes: http://lattes.cnpq.br/0375894180479456. E-mail: dolandeli@gmail.com. 
Abstract: The debate on elections and political representation in Brazil has highlighted women's difficulties to reach elective public office, due, among other factors, to the restraint imposed by the electoral funding system that has been extremely unequal when comparing men and women candidacy. This research main objective is: to evaluate the pattern of financing of women's election campaigns in comparison to men for the Chamber of Deputies, Legislative Assemblies and City Council in the 2014 and 2016 elections. We analyzed the data using descriptive and inferential statistics through estimates of mean, standard deviation, variance and analysis of variance test (ANOVA). Thus, it was found that women collect less resources than men, regardless of the position in dispute, party ideology or region of the country. We observed that the different patterns of women's campaign financing make it difficult to build an inclusive political representation.

Keywords: Elections; campaign financing; political representation.

Resumen: El debate sobre las elecciones y la representación política en Brasil ha puesto de realce las dificultades de las mujeres para alcanzar cargos electivos, debido, entre otros factores, a la restricción impuesta por el sistema de financiación electoral que ha sido extremadamente desigual en la comparación entre hombres y mujeres. Esta investigación tiene como objetivo principal: evaluar el patrón de financiación de las campañas electorales de mujeres en relación con los hombres para la Cámara de Diputados, las Asambleas Legislativas y la Cámara de Concejales en las elecciones de 2014 y 2016 . Analizamos los datos utilizando estadística descriptiva e inferencial a través de estimaciones de la media, desviación estándar, varianza y prueba de análisis de varianza (ANOVA). Por lo tanto, se descubrió que las mujeres recolectan menos recursos que los hombres, independientemente de la posición en disputa, la ideología del partido o la región del país. Observamos que los diferentes patrones de financiamiento de la campaña de las mujeres dificultan la construcción de una representación política inclusiva..

Palabras clave: Elecciones; financiamiento de campañas; representación política. 